\title{
Simulative Potential Analysis of Combined Waste Heat Refrigeration using Ammonia in an Intercity Bus on dynamic route
}

\author{
Maximilian Hebeler ${ }^{1 *}$; Christian Schulze ${ }^{2}$; Wilhelm Tegethoff ${ }^{2}$; Jürgen Köhler $^{1}$ \\ ${ }^{1}$ Institut für Thermodynamik, TU Braunschweig, Germany, \\ ${ }^{2}$ TLK Thermo GmbH, Germany \\ * Corresponding author. Phone:+49 531-391-7892; E-Mail: m.hebeler@tu-bs.de
}

\begin{abstract}
In this work, a simulative potential analysis of a possible topology for combining waste heat recovery and passenger compartment refrigeration using ammonia is carried out. The focus is on the energetic assessment using a detailed simulation model of a long haul intercity bus.

The topology combines a conventional refrigeration cycle with an Organic Rankine Cycle (ORC). Both systems share the working fluid and the condenser. The used refrigerant is Ammonia (R-717). Expansion machine and compressor are both connected to the drive belt of the vehicle. In order to evaluate the fuel consumption reduction potential of that topology the intercity bus simulation model, equipped with a $\mathrm{CO} 2$ (R-744)-refrigeration system, is used as a reference.

The results show that using an Organic Rankine Vapor Compression Cycle (ORVC) equipped with ammonia leads to an effective reduction of fuel consumption for a long-haul journey. The ORVC topology reduces fuel consumption by $7.9 \%$.
\end{abstract}

Keywords: ORC, ORVC, CO2, Ammonia, R-744, R717

\section{Introduction}

The compressor of the Air-Conditioning System (AC) of an intercity bus uses up to $15 \mathrm{~kW}$ of additional mechanical power from the engine, thereby reducing the effective power available for vehicle traction. For a long haul journey of several hundred kilometers, this energy input accounts for around $8 \%$ of the overall diesel fuel consumption. On the other hand, approximately one third of the supplied chemical energy is rejected as hot exhaust gas into the environment and another third is dissipated by the cooling system leaving only one third for vehicle traction. In order to use the exergetic potential of the exhaust gas, a Waste Heat Recovery (WHR) system can be applied, such as an Organic Rankine Cycle (ORC). The recovered energy can be used for reducing the engine load mechanically or by driving auxiliary loads like the alternator or the refrigerant compressor. Therefore, combining the waste heat recovery and the air-conditioning system can be a promising method for reducing primary energy usage. Combining these two systems efficiently is a challenge, as many aspects and interactions have to be considered. The work described in this paper is part of the overall research efforts that aim to develop and compare different topologies and methods for intercity bus climatization using exhaust waste energy. The aim is to completely provide the energy need of the refrigeration system and all its components via the WHR system taking environmental regulations into account. In this work, a preliminary analysis of one possible topology for combined waste heat refrigeration is carried out using a detailed simulation model of a long haul intercity bus equipped with an R-744-refrigeration system. In terms of ORVC, the carried out research is mainly distinguished to other researches (e.g. Yilmaz, 2015; Wang et al, 2011; Saleh, 2016) by using ammonia as working fluid/refrigerant.

\section{Overview of Organic Rankine Vapor Compression Cycle Systems}
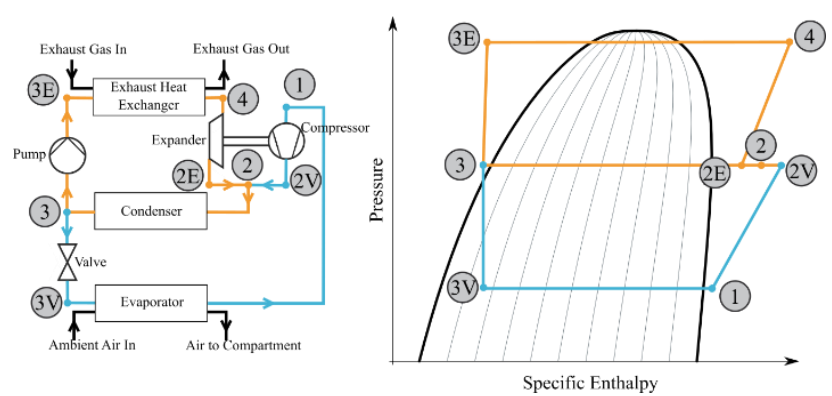

Figure 1. Schematic overview of an Organic Rankine Vapor Compression Cycle. On the left hand side, the diagram shows all essential components, the right hand side shows the corresponding thermodynamic points of state for the working fluid ammonia.

Figure 1 shows an example configuration of an Organic Rankine Vapor Compression Cycle (ORVC), as commonly shown in the literature (e.g. Yilmaz, 2015; Wang et al, 2011; Saleh, 2016). All relevant components and thermodynamic points of state are 
depicted. The conventional refrigeration process, consisting of evaporator, condenser, compressor and expansion valve, is extended by a Rankine Cycle, that receives heat from the engine exhaust stream and converts that thermal energy into mechanical energy by evaporation and expanding the fluid. Expansion machine and refrigereant compressor are mechanically coupled thus the presented process is a combination of a heat engine and refrigeration machine, sharing the same working fluid. The remaining heat of both cycles is rejected via the same condenser on middle pressure level. Depending on the system design, the expansion machine or the compressor can be connected additionally to an auxiliary load or drive. The net power output of the process is defined as follows:

$$
\begin{gathered}
P_{\text {Pump }}+P_{\text {Expander }}+P_{\text {Compressor }}+P_{\text {Fan }} \\
=P_{\text {Net }}
\end{gathered}
$$

\section{Simulation Model and Investigated Topology}

In the following, the investigated topology and its implementation into the omnibus as well as the simulation statistics of the corresponding models are described. All models have been created using the TIL and TIL Media library (Richter, 2008; Gräber et al, 2010; Schulze et al, 2011) in Modelica. In terms of the TIL library a highly dynamic modelling approach has been used. All components can handle zero mass flow rate and flow reversal.

\subsection{Vehicle simulation model}

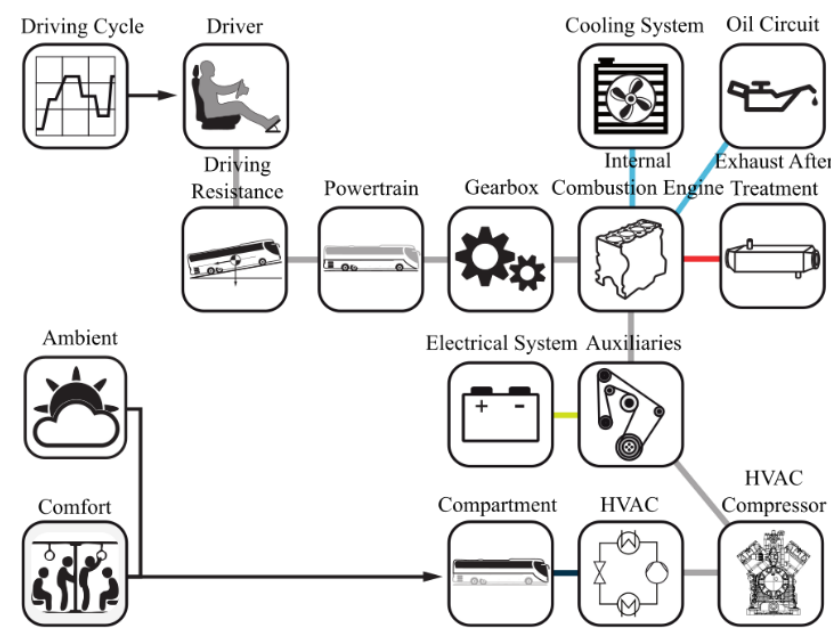

Figure 2. Schematic depiction of the main subsystem interactions of the omnibus as modeled in (Kaiser, 2018). Depiction in dependence on (Ebeling, 2018).

Figure 2 gives an overview of the complete omnibus simulation model and its sub-models. All longitudinal dynamics have been considered. Vertical dynamics have been neglected. The model was created by Kaiser in (Kaiser, 2018) using the object orientated programming language Modelica and has been validated with experimental data.

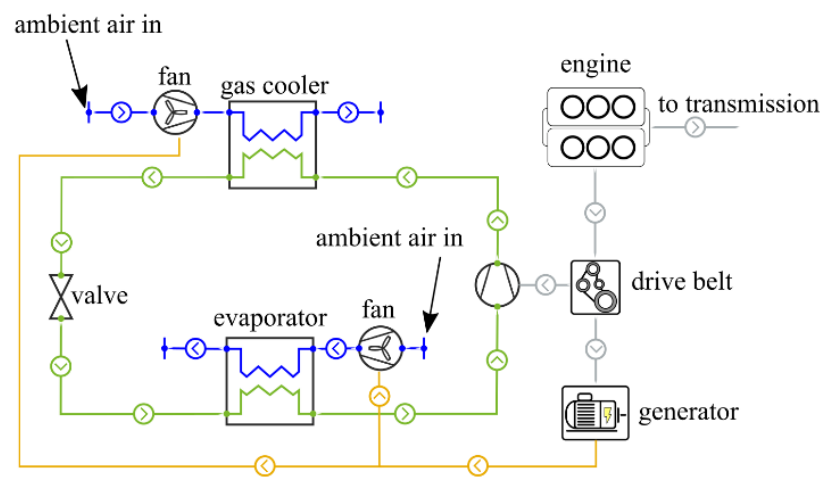

Figure 3. Schematic of the R-744 reference refrigeration system including connections to engine, drive belt and generator. Blue represents air, green represents working fluid and yellow represents electrical current. Mechanical work is depicted in gray.

The actual vehicle represents an omnibus with a passenger capacity of 48 people and an engine peak power of $295 \mathrm{~kW}$. Figure 3 shows the R-744refrigeration system and its connections into the powertrain of the omnibus. The refrigeration system has three evaporators in parallel, one for the climatization of the driver and two for the passenger compartment. For the sake of simplification, Figure 3 shows a simplified version of the refrigeration cycle with only one evaporator for the passenger compartment. The compressor is driven by the drive belt of the combustion engine. All fans are fed by the vehicle's electrical system, respectively the alternator. Further explanation of the refrigeration system can be found in detail in (Kaiser, 2018).

Table 1 summarizes some of the simulation system's statistics for the vehicle simulation model including HVAC-unit.

Table 1. Some of the simulation statistics of the vehicle simulation model (including HVAC-unit)

\begin{tabular}{|l|l|}
\hline Nontrivial Equations & 21189 \\
\hline Continuous time states & 1024 \\
\hline Time-varying variables & 31845 \\
\hline $\begin{array}{l}\text { Number of mixed real/discrete systems of } \\
\text { equations }\end{array}$ & 35 \\
\hline $\begin{array}{l}\text { Highest number of non-linear equations } \\
\text { after manipulation }\end{array}$ & 3 \\
\hline $\begin{array}{l}\text { Number of systems of equations with size } \\
\text { of } 3\end{array}$ & 2 \\
\hline $\begin{array}{l}\text { Number of systems of equations with size } \\
\text { of } 2\end{array}$ & 0 \\
\hline $\begin{array}{l}\text { Number of systems of equations with size } \\
\text { of } 1\end{array}$ & 51 \\
\hline
\end{tabular}




\subsection{Organic Rankine Vapor Compression simulation model}

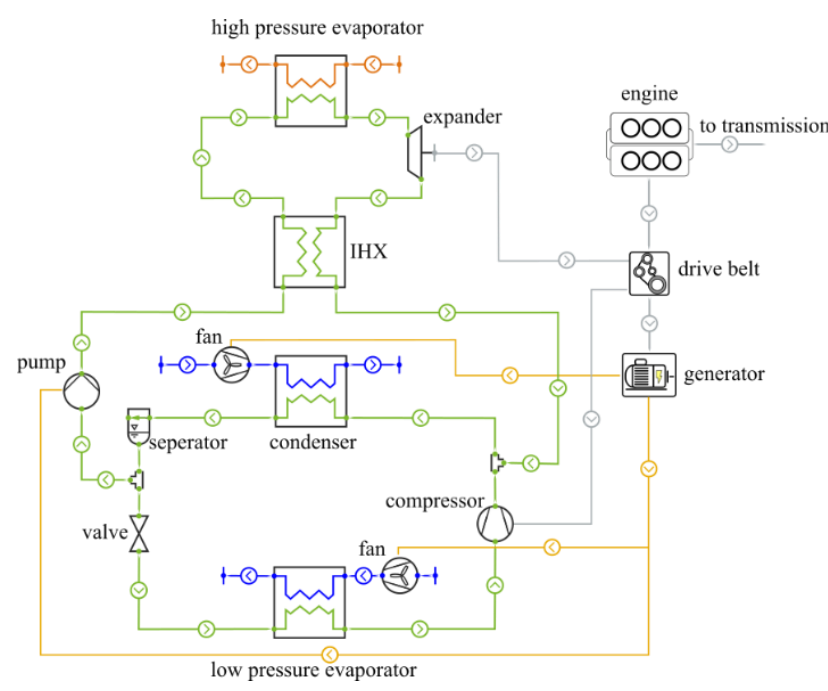

Figure 4. Schematic of the ORVC-topology including connections to engine, drive belt and alternator. Orange represents exhaust gas, blue represents air, green represents working fluid and yellow represents electrical current. Mechanical work is depicted in gray.

Figure 4 shows the ORVC-topology and its connections into the powertrain of the omnibus. This topology is a combination of an $\mathrm{R}-134$ a refrigeration system and an ordinary ORC-topology. The condenser of the refrigeration system replaces the ORC-condenser. The expected condensation heat is approximately twice the condensation heat of the original refrigeration system, hence the size of the condenser is doubled. The number of condenser fans is increased as well. The expansion machine and the compressor are both coupled to the drive belt. The expansion machine is assumed to have a constant overall efficiency of $70 \%$. Finally, the gear ration between compressor and drive belt is changed in order to achieve the same cooling power as in the original R-134a system. In terms of working fluid ammonia (R-717) is chosen as a drop-in, since it is a natural refrigerant (GWP and ODP $=0$ ) with a high volumetric cooling capacity and a good compromise in usability as a working fluid in terms of waste heat recovery. The fundamental equation of state of ammonia was implemented as a multi parameter equation of state as in (Tillner-Roth et al,1993; Span et al, 1996), therefore there was no interpolation routine necessary. It has to be pointed out, that in this context it has not been taken into account that the use of R-717 in direct evaporation systems can lead to grave safety issues, since it is a highly toxic substance. This study is supposed to be a simulative potential study of ammonia as a working fluid in ORVC systems with respect to highly transient boundary conditions.

For controlling the pump speed, a PI-Controller is used, which sets the outlet state of the expansion machine to $60 \mathrm{~K}$ superheated vapor. In that manner, the following internal heat exchanger is provided with enough temperature difference to transfer heat from mid pressure to high pressure level. Table 2 summarizes the control concept of the presented ORVC topology.

Table 2. PI-Controller assignment for the presented ORVC topology

\begin{tabular}{|l|l|}
\hline Actuating Variable & Controlled Variable \\
\hline pump speed & $\begin{array}{l}\text { overheating at expander } \\
\text { outlet }\end{array}$ \\
\hline condenser fan speed & mid-pressure level \\
\hline evaporator fan speed & $\begin{array}{l}\text { air inlet and compartment } \\
\text { temperature }\end{array}$ \\
\hline valve eff. flow area & $\begin{array}{l}\text { overheating at evaporator } \\
\text { outlet }\end{array}$ \\
\hline
\end{tabular}

The described topology is similar to (Yilmaz, 2015), where R-134a and R-245fa are investigated as working fluid. In (Yilmaz, 2015), compressor and expander are directly coupled with no other external connection. However, in this work the expansion machine and the compressor are coupled via the drive belt of the vehicle. Hence, the shaft work of expander and compressor may be unequal, so that power is drawn from or supplied to the engine. Furthermore, as mentioned, in this work ammonia is used as working fluid.

Table 3 summarizes some of the simulation system's statistics for the vehicle simulation model including the ORVC-topology. Despite the system size, the presented model offers an integration time close to real-time on a standard Desktop-PC. In comparison to the reference model (see. Table 1), the number of nontrivial equations has increased. Still, the number of nonlinear systems of equations remains the same.

Table 3. Some of the simulation statistics of the vehicle simulation model (including ORVC-topology)

\begin{tabular}{|l|l|}
\hline Nontrivial Equations & 22992 \\
\hline Continuous time states & 1053 \\
\hline Time-varying variables & 36176 \\
\hline $\begin{array}{l}\text { Number of mixed real/discrete systems } \\
\text { of equations }\end{array}$ & 35 \\
\hline $\begin{array}{l}\text { Highest number of non-linear equations } \\
\text { after manipulation }\end{array}$ & 3 \\
\hline $\begin{array}{l}\text { Number of systems of equations with } \\
\text { size of } 3\end{array}$ & 2 \\
\hline $\begin{array}{l}\text { Number of systems of equations with } \\
\text { size of } 2\end{array}$ & 0 \\
\hline $\begin{array}{l}\text { Number of systems of equations with } \\
\text { size of } 1\end{array}$ & 51 \\
\hline $\begin{array}{l}\text { CPU-Time for integration of 37622 s of } \\
\text { simulation time }\end{array}$ & $3.38 \mathrm{e} 4 \mathrm{~s}$ \\
\hline
\end{tabular}


(a)

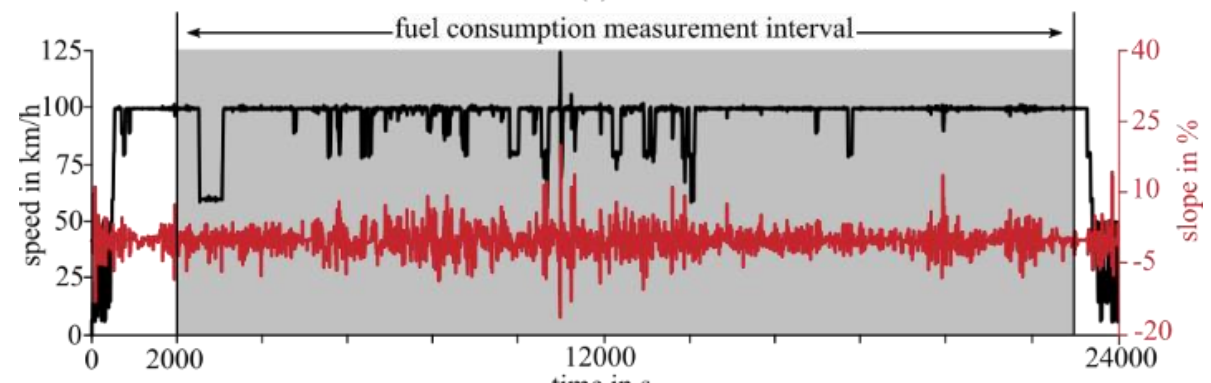

(b) time in $\mathrm{s}$

(c)
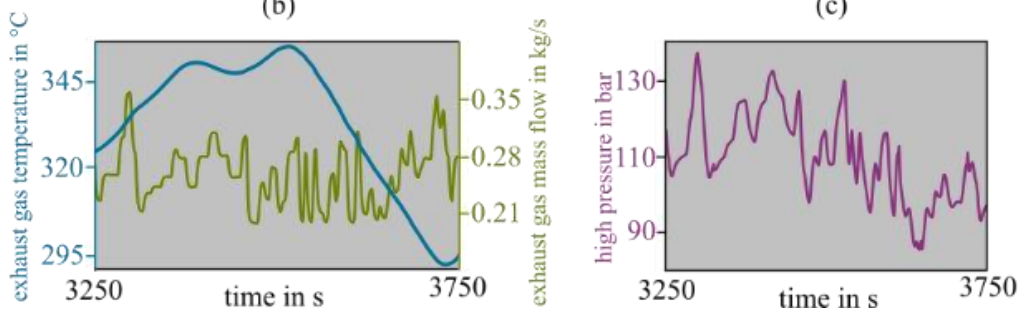

Figure 5. Real life driving scenario from Hanover to Munich (Kaiser, 2018). Vehicle speed and slope of route depicted with respect to time (a). System input boundary conditions (b) and system response of pressure at high pressure evaporator outlet (c) for a representative time interval of $3250 \mathrm{~s}$ to $3750 \mathrm{~s}$.

\section{Boundary Conditions and Simulation Results}

In order to evaluate the integration of the presented topology into the vehicle, a real driving scenario from Hanover to Munich is applied as simulation input. The scenario considers vehicle speed, slope of route and weather conditions. For the applied scenario a typical august summer day has been chosen, further details are explained in (Kaiser, 2018). Figure 5 shows the vehicle speed over time and the corresponding driving slope. In case of the ORVC-topology the system is only activated during highway conditions. As a consequence the fuel consumption measurement interval has been chosen from 2000 until 23000 seconds of the journey. The mentioned interval is depicted in Figure 5, as well. The results are compared to the reference only in that time period. In terms of the ORVC configuration, the exhaust gas evaporator is integrated after the SCR-catalyst of the exhaust after treatment system of the vehicle.

In all simulations the Dassl's integration method has been used with a solver tolerance of 1e-5. The output interval has been set to $1 \mathrm{~s}$.

\subsection{Evaluation Parameters}

The exergetic efficiency is defined as the ratio of the net power of the process and the provided exhaust gas exergy at the exhaust gas heat exchanger inlet:

$$
\eta_{\text {ex }}=\frac{-P_{N e t}}{\dot{E x_{\text {inlet }, \text { Gas }}}}
$$

However, for positive values of the net power of the process (the process draws power), the exergetic efficiency is negative. In the shown results this is usually the case, since the drawn power of the refrigeration system exceeds the provided power of the waste heat recovery system. It is therefore more feasible to introduce the so called Work Number (WN), which gives the ratio of the cooling heat to the necessary work input of the whole process:

$$
W N=\frac{\int \dot{Q}_{\text {Evaporator }} d t}{\int P_{\text {Net }} d t}
$$

\subsection{Results}

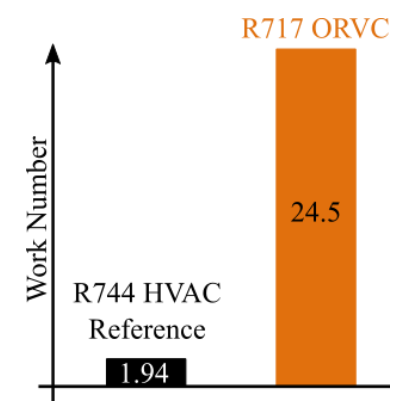

Figure 6. Overview of the Work Number for the evaluated topologies for the period of a real life driving cycle from Hanover to Munich between 2000 and 23000 seconds of the journey.

Figure 7 shows the result for the exergy analysis in the mentioned driving scenario for the reference system and the mentioned topology. Exergy source and exergy demand are compared to each other. The exergy balance is formed around the engine, the drive belt and the gearbox, taking all necessary consumers into account. The exergy demand is hereby divided into driving resistance and gearbox losses, engine auxiliaries (all kinds of 
consumers like pumps or fans etc.), vehicle auxiliaries (lighting and electronic control units etc.), HVAC auxiliaries (condenser and evaporator fans and control units), compressor shaft power and the resulting drive belt losses. Electrical conversion losses of the electrical components are included as exergy demand of the corresponding component. In case of ORVC applications the exergy demand of the pump is depicted as well. As exergy source the corresponding component is depicted in opposition and is divided into engine crankshaft and, if existing, expansion machine.

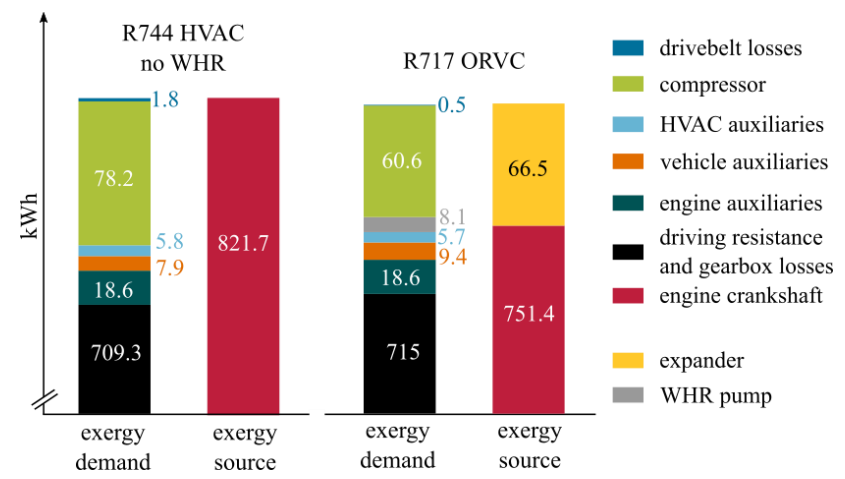

Figure 7. Exergy demand and source for the evaluated topologies for the period of a real life driving cycle from Hanover to Munich between 2000 and 23000 seconds of the journey.

It can be seen that the exergy demand covered by the engine decreases from the reference system without WHR to the ORVC topology. The exergy output of the engine decreases by $8.6 \%$ compared to the reference. This decrease corresponds to a fuel consumption decrease by $7.9 \%$. The reason for this decrease is mainly due to the WHR system, since the expansion machine reduces the engine load, as mentioned above. In addition to that, the change of the refrigerant from R744 to R-717 already has a notable influence. The necessary work input for the compressor is reduced by almost $23 \%$, which already improves fuel efficiency. The mentioned change in condenser size and the increase in the number of condenser fans do not seem to have a noticeable effect on the HVAC auxiliaries' exergy demand. Figure 6 shows the work number of the simulated topology in comparison to the system without WHR taking all work in and outputs into account. It can clearly be stated, that in case of the ORVC topology the necessary work input into the system is twelve times lower than in case of the reference system with no WHR.

Still, the impact of the expansion machine on the drive train of the engine has to be taken into account. As mentioned, in both topologies identical boundary conditions were applied. Due to that, the exergy demand for the driving resistance should be equal in all simulations. As shown in Figure 7, this is not the case.
The driving resistance differs by about $6 \mathrm{kWh}$ in case of the ORVC topology compared to the reference. Because of the thermal capacity of the WHR and the exhaust manifold, the time constant of the WHR is several magnitudes bigger than that of the drivetrain's mechanics, hence the expansion machine is still providing energy while the driver is applying the brake pedal. Due to the additional power input of the expansion machine into the drive train, the driver, represented by a PI-controller, tends to accelerate and decelerate more aggressively, which leads to the shown increase in driving resistance, respectively fuel consumption. Consequently, the fuel reduction potential for the shown ORVC configuration is slightly higher than depicted in Figure 6 and Figure 7 respectively. The adaption of the driver model as function of drivetrain design is part of future work of the author.

\section{Summary \& Discussion}

In this work, a simulative preliminary comparison of a possible topology for combined waste heat refrigeration has been carried out using a detailed simulation model of a long haul intercity bus. The shown topology implements an Organic Rankine Vapor Compression Cycle into the vehicle, where the refrigeration system and the waste heat recovery system share the refrigerant and condenser. The refrigeration side of the shown topology is derived from an R-134a refrigeration system. The applied refrigerant is Ammonia (R-717). Expansion machine and compressor are both connected to the drive belt of the vehicle. As study reference, the intercity bus model equipped with an R-744-refrigeration system is used.

The simulation results show that with the applied topology and parameters it is possible to effectively decrease the fuel consumption of an intercity bus on a long haul journey under dynamic boundary conditions. Furthermore it has been shown, that the dynamic modelling approach enables the transient simulation of large processes in a time-efficient manner without sacrificing accuracy in physical behavior.

Still, it has to be stressed, that in this comparison it has not been taken into account that the use of R-717 in direct evaporation systems can lead to grave safety issues, since it is a highly toxic substance. The scope of future work is therefore to implement an ORVC in combination with an intermediate evaporation system. It has to be evaluated, if yet a fuel reduction potential is given. In that case the use of an ORVC with R-717 is highly promising, since the needed cooling load can be maintained with simultaneously meeting environmental regulations, such as GWP and ODP.

Apart from that, it has to be pointed out, that further extended research has to be carried out in order to compare the two systems. Several effects have not been analyzed, which could improve or limit the presented ORVC performance. To highlight all these effects goes 
beyond the scope of this work and will be presented in future publications.

\section{Acknowledgements}

Parts of this publication have been developed with funding from the German Federal Ministry of Education and Research (BMBF) within the research project VEOS - Verfahren zur energetischen Optimierung dynamischer thermischer Systeme (KMU Innovativ, 01 | LY1502) and VEOTOP - Verfahren zur optimalen Synthese und Topologieoptimierung komplexer thermischer Energiesysteme (KMU Innovativ, 01 | LY1809B)

\section{References}

Yilmaz, A.: Transcritical organic Rankine vapor compression refrigeration system for intercity bus air-conditioning using engine exhaust heat. Energy 82 (2015) 1047-1056.

Saleh, B.: Parametric and working fluid analysis of a combined organic Rankine-vapor compression refrigeration system activated by low-grade thermal energy. Journal of Advanced Research (2016) 7, 651-660

Kaiser, C.: Untersuchungen zur Effizienz- und Leistungsverbesserung von Omnibusklimaanlagen. $\mathrm{PhD}$ thesis, TU Braunschweig (approx. published in 2018)

Richter, C.: Proposal of New Object-Oriented Equation-Based Model Libraries for Thermo-dynamic Systems. PhD thesis, TU Braunschweig (2008)

Schulze, C., Gräber, M., Huhn, M., and Grätz, U.: Real-Time Simulation of Vapour Compression Cycles. In: Proceedings of the 8th International Modelica Conference, Dresden (2011)

Wang, H., Peterson, R., Herron, T.: Design study of configurations on system COP for a combined ORC (organic Rankine cycle) and VCC (vapor compression cycle). Energy 36 (2011) 4809-4820.

Gräber, M., Kosowski, K., Richter, C., and Tegethoff, W.: Modelling of heat pumps with an object-oriented model library for thermodynamic systems. Mathematical and Computer Modelling of Dynamical Systems, 16(3):195209., (2010)

Ebeling, P.: Konzeption eines Rankine-Prozesses für den transienten Betrieb im Omnibus, $\mathrm{PhD}$ thesis, TU Braunschweig (approx. published in 2018)

Tillner-Roth, R., Harms-Watzenberg, F., and Baehr, H.D., In: Eine neue Fundamentalgleichung fuer Ammoniak, DKVTagungsbericht, 20:167-181, 1993.

Span, R. and Wagner, W.: A New Equation of State for Carbon Dioxide Covering the Fluid Region from the TriplePoint Temperature to $1100 \mathrm{~K}$ at Pressures up to $800 \mathrm{MPa}$, In: J. Phys. Chem. Ref. Data, 25(6):1509-1596, 1996.", 